\title{
Assessment of recent changes in dust over South Asia using RegCM
}

\author{
A. Asutosh ${ }^{1,2^{*}}$, S. K. Pandey ${ }^{1}$ and V. Vinoj ${ }^{1}$ \\ ${ }^{1}$ School of Earth, Ocean and Climate Science \\ Indian Institute of Technology Bhubaneswar, Bhubaneswar, Odisha, INDIA - 752050 \\ ${ }^{2}$ National Centre for Polar and Ocean Research, Ministry of Earth Sciences, Goa, INDIA- 403804 \\ Correspondence: asutosh.acharya@gmail.com
}

\begin{abstract}
Pre-monsoon dust aerosols over Indian regions are closely linked to the monsoon dynamics and Indian summer monsoon rainfall. Past observational studies have shown a decline in dust loading over the Indian landmass potentially caused by changing rainfall patterns over the desert regions. Such changes are expected to have far reaching impact on regional energy balance and monsoon rainfall. Using a regional climate-chemistry model, RegCM4.5 with an updated land module, we have simulated the long-term (2001-2015) changes in dust over the arid and semi-arid dust source regions of the North-Western part of the sub-continent. It is found that the area-averaged dust aerosol optical depth (AOD) over the arid and semi-arid desert regions has declined by $17 \%$ since the start of this millennium. The rainfall over these regions exhibits a positive trend of $0.1 \mathrm{~mm}^{\mathrm{day}}{ }^{-1} \mathrm{year}^{-1}$ and a net increase of $>50 \%$. The wet deposition is found to be dominant and $\sim 5$ fold larger in magnitude over dry deposition and exhibits total changes of $\sim 79 \%$ and $48 \%$ in the trends in atmospheric dust. As a response, significant change in the surface (11\%), top of the atmosphere radiative forcing $(7 \%)$, and widespread atmospheric cooling are observed in short wave domain of radiation spectrum, over the Northern part of the Indian landmass. Such quantification and long term change studies are necessary for understanding the regional climate change and the water cycle.
\end{abstract}

Keywords: dust aerosols, radiative forcing, regional climate, rainfall, RegCM 


\subsection{Introduction}

Mineral dust (or dust) is one of the most important sources for aerosol mass in the atmosphere (I Tengen, 1995). They are of various size ranges and exert a radiative effect in both the solar and terrestrial radiation known as the aerosol direct effect (Atwater, 1970; Charlson et al., 1992; Ensor et al., 1971). Based on their hygroscopic nature and secondary mixing, the dust aerosols also have an effect on the radiation by affecting cloud microphysics, known as the indirect effect (Dipu et al., 2013; Gu et al., 2012; Twomey, 1977). Dust is known to have a strong influence on both regional and global climate (Lau et al., 2006; Sanap and Pandithurai, 2015).

The abundance of mineral dust over India makes the overall aerosol burden about three times higher than the global average, especially during summer and monsoon seasons (Dey et al., 2004). The primary sources of dust over the Indian landmass are the arid and semi-arid regions (mostly northwestern and adjacent parts of India) and long-range transport from middle-west Asia and North Africa by the westerly winds (Das et al., 2015a; Jin et al., 2015; Lau, 2016; Maharana et al., 2019; Pandey et al., 2017; Vinoj et al., 2014). It peaks during Apr/May and declines thereafter due to the arrival of monsoon and enhanced wet deposition (Lau, 2016; Maharana et al., 2019).

The direct and indirect effects take place simultaneously, interacting with each other. This adds more complexity to the overall forcing and responses of the hydrological cycle over the South Asian/Indian monsoon system (Lau et al., 2009). Dust is known to alter atmospheric dynamics through warming, thereby impacting the atmospheric circulation (Dash et al., 2015; Harikishan et al., 2015; Jin et al., 2015). Many studies highlight the short and long term impacts of remote/local aerosols to monsoon rainfall through elevated heat pump (EHP) mechanism solar dimming and local and remote atmospheric heating processes (Bollasina et al., 2008; Chung et al., 2002; Jin et al., 2015; Lau and Kim, 2011; Maharana et al., 2019; Nigam and Bollasina, 2010; Vinoj et al., 2014). The presence of absorbing aerosols like dust and black carbon over parts of northern India and the Himalayan foothills could enhance monsoon rainfall in subsequent months (June/July) through dynamical feedback (Lau 
52

53

54

55

et al., 2006, 2016). Therefore, variations in the summer dust cycle could inevitably impact the monsoon hydrology by altering the regional radiation balances, thereby atmospheric dynamics.

Limited studies have highlighted the pre-monsoon dust changes over the arid and semi-arid (dust sources) regions of India (Pandey et al., 2016). Pandey et al. 2017, made the first attempt to investigate the long-term aerosol/dust dynamics during the pre-monsoon season over India. The complex forcing and feedback mechanisms renders, elucidating the effects of changes to dust and their regional climate interaction from other large scale forcing. Further, there are no well accepted direct measurements to distinguish dust optical and radiative properties of total aerosols from space. Hence, a model can be an optimal solution for exploring dust processes and their optical and radiative properties. The inadequate representation of various processes, coarse spatial resolution of soil data, and meteorological fields in typical global climate model (GCM's) make it difficult to study dust and its feedback at regional scales. This makes the choice of a regional climate model (RCM) better over the global models (Dickinson et al., 1989; Gao et al., 2006; Giorgi, 2019; Giorgi et al., 2012; Giorgi and Marinucci, 1991; Oh et al., 2014) with its higher spatial resolutions, better parameterization and capacity to resolve sub-grid processes (Giorgi, 2019; Solmon et al., 2006).

In this paper, a regional climate model (RegCM4.5) is used to understand changes to dust aerosol loading over the arid regions to the North-western of the subcontinent. The study specifically explores the relationship between rainfall, dust emission and its atmospheric loading. In addition, the changes (quantification) in short and long wave radiation at surface, atmosphere and top of the atmosphere during period are elucidated.

\subsection{Data and Methodology}

\subsection{Regional climate model RegCM (version 4.5):}

The fourth generation of Abdus Salam International Centre for Theoretical Physics (ICTP) regional climate model (RegCM version 4.5) is used to carry out this study (Giorgi et al., 2016, 2012). 
RegCM's dynamical core is based on the hydrostatic version of the mesoscale model MM5 of the National Center for Atmospheric Research and is widely used (Dash et al., 2013; Davitashvili et al., 2018; Georg et al., 1994; Pattnayak et al., 2019). Radiative transfer in RegCM uses the parameterization of NCAR's community climate model CCM (Kiehl et al., 1996). The model's capability in simulating aerosols and their various optical properties (Abish and Arun, 2019; Ajay et al., 2019; Maharana et al., 2019) has been utilised for various applications. Also, it captures the mean patterns and climatological features other meteorological parameters (temperature, wind, precipitation etc.) over Indian regions (Ajay et al., 2019; Maurya et al., 2017; Mohanty et al., 2019; Pattnayak et al., 2018; Tiwari et al., 2015). RegCM4.5 has both online dust and anthropogenic aerosol modules, hence is widely used to study the aerosol-climate interactions (Abish and Arun, 2019; Ajay et al., 2019; Das et al., 2015b; Maharana et al., 2019; Nair et al., 2012; Solmon et al., 2006). The dust module is designed to be online, i.e., it works in two-way coupling with meteorology. This is one of the major advantages over other offline (one way interacting) model. The online dust module follows the parameterization scheme developed by (Alfaro and Gomes, 2001). The module has major features like dust emission, dry and wet deposition, transport, optical properties, and direct radiative forcing (Zakey et al., 2006). This dust module divides the size distribution of the dust particles into four bins varying from finer $(0.01-1.0 \mu \mathrm{m}$ and $1.0-2.5 \mu \mathrm{m})$ to coarser dust aerosols $(2.5-5.0 \mu \mathrm{m}$ and 5.0-20.0 $\mu \mathrm{m}$ ). The model uses Mie theory to estimate the aerosol optical and radiative properties (Davitashvili et al., 2018; Santese et al., 2003; Zakey et al., 2006). For the refractive index of dust aerosols, the model uses the Optical Properties of Aerosols and Clouds (OPAC) database (Hess et al., 1998; Zakey et al., 2006). The complexity and representation of the land model play a vital role in dust generation in RegCM. The default is the BATS (Biosphere atmosphere transfer scheme), and two community land models (CLM3.5 and CLM4.5) options are available for coupled land-atmosphere configurations. However, the benefits of CLM 4.5 over BATS and CLM, as the former has more soil layers, vegetation fractions and uses subgrid "tiles" method where separate water and energy balance for each tile is performed (Ajay et al., 2019; Steiner et al., 2009). This method aims to model the 
104 surface parameters better than the default BATS scheme. Therefore, the CLM4.5 model has been used

105 for dust simulation in the present study.

106 2.2. Experimental design and data set used

107 The simulations are carried out at $50 \mathrm{~km}$ spatial resolution, and the initial and lateral boundary 108 conditions are forced with 6-hourly ERA-interim $1.5^{\circ} \times 1.5^{\circ}$ gridded reanalysis data. The sea surface

109 temperature data are extracted from the National Oceanic and Atmospheric Administration (NOAA)

$1101.0^{\circ} \times 1.0^{\circ}$ weekly data set. The land use data and terrain heights are generated from the United States

111 Geographical Survey at 30s resolution. A total of 15 years (2001-2015) of simulations have been

112 performed starting from $1^{\text {st }}$ March to $31^{\text {st }}$ May each year. In the present analysis, only data from May

113 is used. Fig.1. (a) depicts the model run domain for this study, and Fig.1. (b) shows the various

114 dominant soil categories associated with the land model (CLM45). The model configurations and

115 other details used for this study are provided in table 1.

116
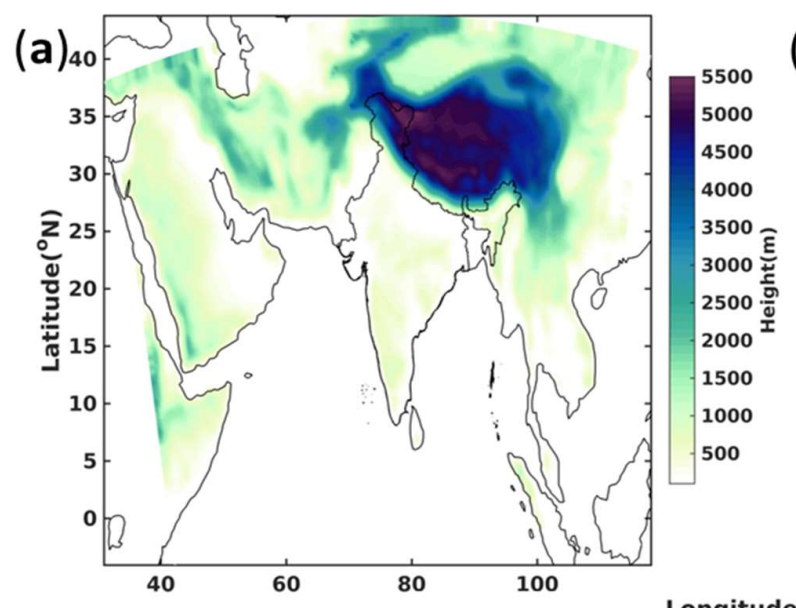

117

Longitude $\left({ }^{\circ} \mathrm{E}\right)$

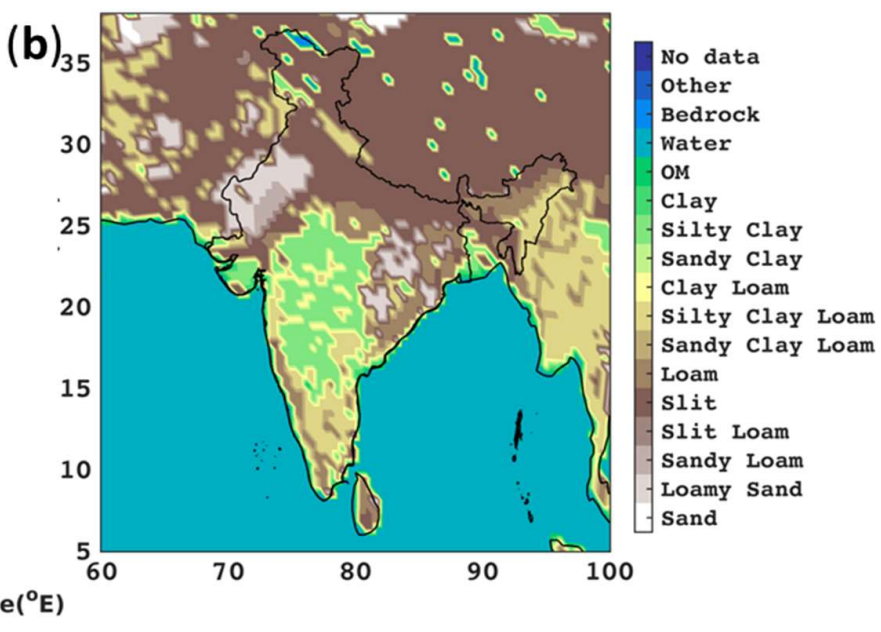

118 Fig.1.(a) The model domain with topographical height (shaded), (b) associated soil texture dominant 119 categories.

120 
122 Table 1 Model configuration implemented for this study

\begin{tabular}{ll}
\hline Model Used & RegCM ( version 4.5) \\
Grid dimensions & 160 x 100, 18 sigma levels \\
Dynamics & MM5 hydrostatic \\
Horizontal resolutions & $50 \mathrm{~km}$ \\
Simulation Periods & $2001-2015$ \\
Top layer Pressure & $50 \mathrm{hPa}$ \\
Land Surface model & CLM4.5 \\
Meteorological boundary conditions & ERA-Interim (Dee et al., 2011) \\
Chemical boundary conditions & Dust Chemistry (online) \\
Cumulus convection scheme & Emanuel over land and ocean \\
Radiation scheme & CCM3 \\
Moisture scheme & Sub-grid Explicit Moisture Scheme \\
& (Pal et al., 2000) \\
Planetary boundary layer scheme & Holtslag PBL (Holtslag et al., 1990) \\
Topography & USGS \\
SST & Weekly Optimal Interpolation dataset \\
& (OI_WK) \\
Dust tracers & DUST4 (4 bins) \\
Dust size particle distributions & Standard scheme (Zakey et al., 2006) \\
\hline
\end{tabular}

123

\section{3.0. Results and Discussion}

125 This section explains the simulated spatial pattern and trends of dust AOD, rainfall, tracer burden, 126 and radiative parameters related to dust. The results section is divided into two parts. The first part 127 explains the spatial trends of the parameters mentioned above. In the second part, we calculate the 128 long-term area-averaged temporal trends of these parameters over the North Western (NW) parts of 129 India and the adjacent regions (NW box hereafter, marked as the dotted rectangular box in Fig.2). The 130 dotted rectangular box delineated over $23.5^{\circ} \mathrm{N}-33^{\circ} \mathrm{N}$ latitude and $66.5^{\circ} \mathrm{E}-74^{\circ} \mathrm{E}$ longitude is our 131 region of interest. This region is chosen as the significant deserts in the Indo-Pak (Thar, Thall, and

132 Cholistan deserts) falls within them. This area is the primary dust source contributing to the total dust 133 AOD load over India during the summer season. We further discuss the implications of the changes 134 in the above parameters to the regional climate. 


\subsection{Trends in AOD and precipitation}
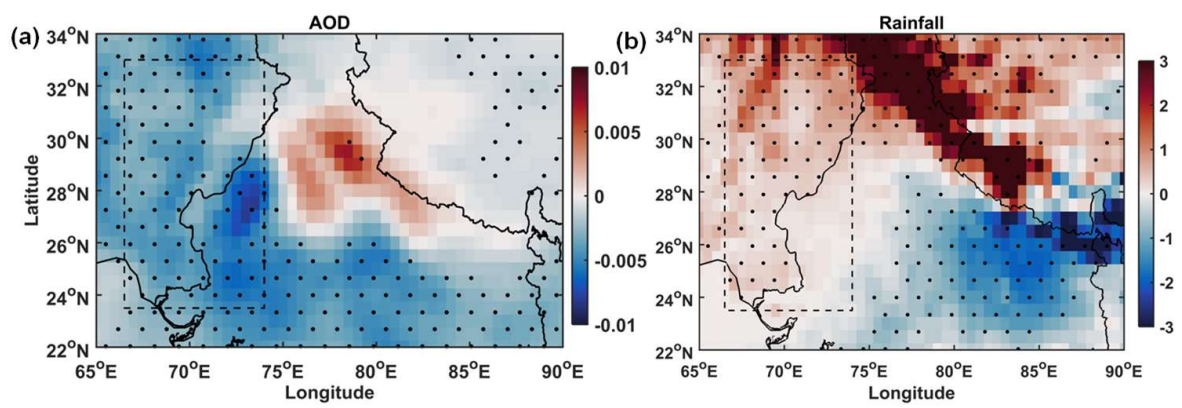

137

138

139

140

141

142

143

144

145

146

147

148

149

150

151

152

153

154

155

156 box).

157 In order to find the possible pathway of the dust/AOD reduction, we further investigated the

158 associated change in the tracer (dust) emissions, its burden, and deposition. Those are discussed in 159

Fig.2. (a) Trends (Year ${ }^{-1)}$ for simulated dust AOD and Precipitation (b) for the period of study. The stipple show the area where trends are significant at 95\% confidence level, determined using MannKendall Trend Tests

The spatial trend of simulated aerosol optical depth (AOD) for May (2001-2015) is shown in Fig.2.

The simulated pattern is similar to that observed using MERRA2 (Modern-Era Retrospective analysis for Research and Applications, version 2, Fig S1a \& S1b). The AOD shows a declining trend over the whole NW part and significant parts of central Indian regions. The signal is robust, especially within the study area of interest (dotted black box). It attains the maximum negative trends $\left(\sim-0.1\right.$ year $\left.^{-1}\right)$ over the Thar Desert regions. However, there is a slightly positive trend observed east of the area of interest, though not statistically significant ( $p>>0.05$ ). To find the cause behind the decline in AOD trends, the simulated precipitation trend during the same period (Fig 2b) is also explored. The precipitation trends resemble that observed using the University of Delaware (UDel) precipitation data (Fig S1c). It shows a strong positive trend over the NW (especially over Pakistan). However, there is a sharp reduction in simulated precipitation trends covering parts of Central India and located east of the area of interest. It may be noted that the simulated trend in AOD and the precipitation over the rectangular box are in the opposite phase. The observed aerosol reduction further to the east might be due to suppression of dust transport from the source regions (here, the area covering the rectangular the subsequent sections. 


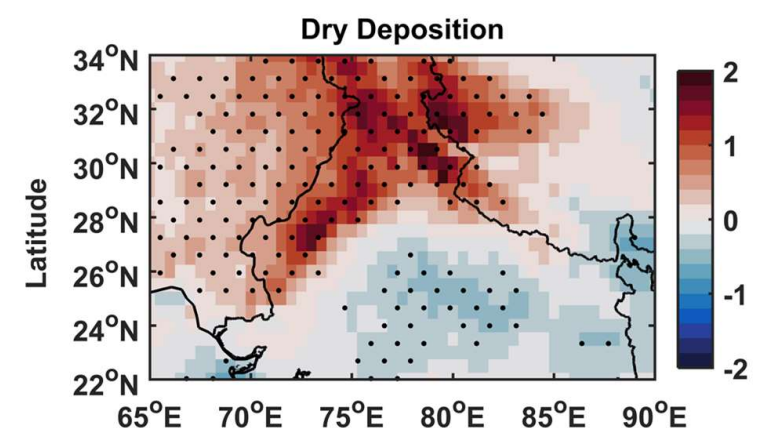

161

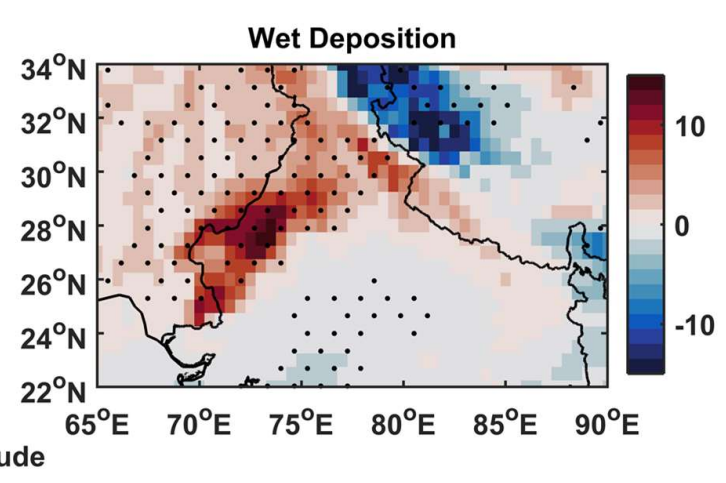

Fig.3. Trends $\left(\right.$ Year $^{-1)}$ in deposition (Dry and Wet, $\mathrm{mgm}^{-2} \mathrm{day}^{-1}$ ) for the period of study. Stipple shows the area where trends are significant at $95 \%$ confidence level, determined using the Mann-Kendall trend tests

162 The Surface emission and the dust burden are primarily controlled by the wind speed and soil texture 163 in the RegCM (Giorgi et al., 2016; Zakey et al., 2006). On the other hand, the dust removal from the 164 atmosphere is controlled by the dry and wet removal processes (due to gravity and rain, respectively). Dust column burden is directly linked to the surface-emission (from the surface to atmosphere), loss (due to dry deposition and wet deposition), and transport (by wind). The dust column burden follows the trend as observed for AOD (not shown). Fig.3 explains the trend of two major dust removal processes. It is clear that both the dry deposition (gravity settling) and wet deposition (washout due to rain) shows a positive trend over the NW box. The positive trend in tracer loss (combined effect of dry and wet deposition) is contributing to a reduction in aerosol optical depth. Also, the wet deposition exceeds dry deposition more than five folds in magnitude when averaged over the NW box (see Table 2). This signifies that rain is one of the primary causes of dust removal from the atmosphere, hence

173 responsible for the negative AOD trends, as observed in Fig. 1.

174 It is established that pre-monsoon dust contributes large fractions to annual average AOD over Indian

175 landmass (Deepshikha et al., 2006; Pandey et al., 2016; Satheesh and Srinivasan, 2002; Vinoj and 176 Satheesh, 2003). Previous studies suggest the dust load/AOD during Apr-May has a role in 177 modulating the rainfall during monsoon months through elevated heat pump mechanism (Lau and 178 Kim, 2006; Lau, 2014; Maharana et al., 2019). Thus, long/short term changes in dust loads/ absorbing 
179 AOD can impact regional climate and hydrological cycles. As regional climate is controlled mainly

180 by the change in radiative balance over that region, a positive (negative) radiative balance leads to

181 warming (cooling). It is to be noted that dust is well known to interact with both short and longwave

182 radiation. Therefore, this decline in dust load is expected to change the regional radiative balance in

183 near-surface (boa), top of the atmosphere (toa), and in the atmosphere (atm). The details of which are

184 discussed in the next section.

\subsection{Changes in radiative forcing and heating rate}
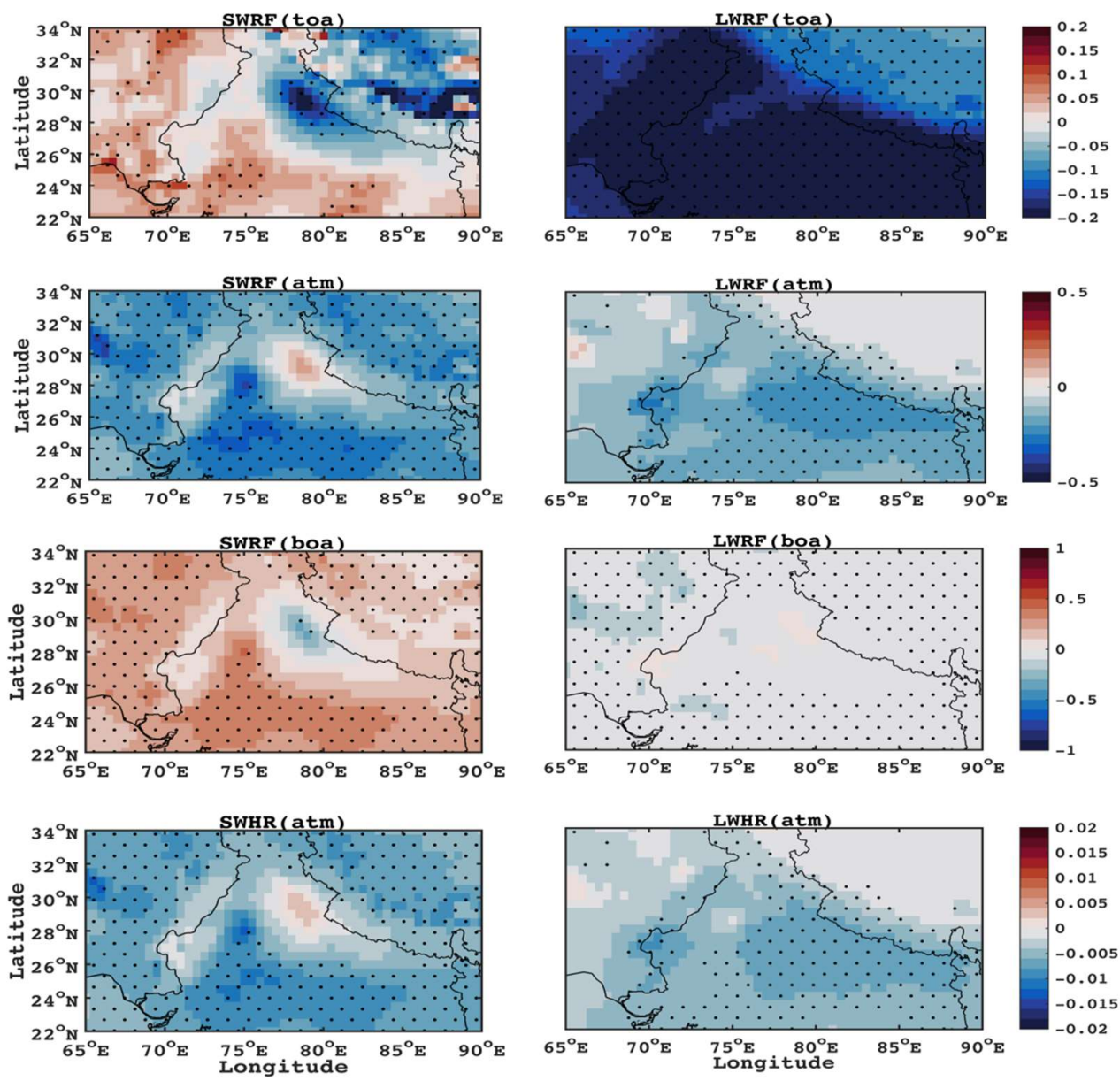

187 Fig.4. The trends (Year ${ }^{-1)}$ in simulated Radiative forcing and heating rate (SW and LW). The terms 188 toa, boa, and atm are acronym for "Top of the atmosphere", "bottom of the atmosphere" and "in the 189 atmospheric column" respectively. The stipple shows the area where trends are significant at $95 \%$ confidence level, determined using the Mann-Kendall trend test

192 The aerosol (dust) radiation interactions is known to be direct radiative forcing (DRF or RF), which 193 is meant to study the climate implication of aerosols. It is calculated as the change in radiative fluxes 
194 (incoming minus outgoing) considering with and without aerosol conditions. The DRF is estimated 195 at the top of the atmosphere $\left(\mathrm{RF}_{\text {toa }}\right)$ as well as the surface/bottom of the atmosphere $\left(\mathrm{RF}_{\mathrm{boa}}\right)$. The direct

196 atmospheric forcing $\left(\mathrm{RF}_{\mathrm{atm}}\right)$ is the difference between radiative forcing at the top and bottom of the 197 atmosphere as follows.

$$
\mathrm{RF}_{\mathrm{atm}(\mathrm{SW}, \mathrm{LW})}=\mathrm{RF}_{\text {toa }(\mathrm{SW}, \mathrm{LW})}-\mathrm{RF}_{\mathrm{boa}(\mathrm{SW}, \mathrm{LW})}
$$

In the above equation, SW/LW denotes the radiative calculation both in the shortwave or longwave radiation spectrum. Dust is known to behave differently in the shortwave (SW) and longwave (LW) spectrum of radiation. Hence we have investigated them separately. All the units of radiative forcing are in $\mathrm{Wm}^{-2}$.

Fig. 4 shows the trend in radiative forcing (RF) simulated by the model. The left four panels of Fig.4, depicts the long term changes in shortwave radiative (toa, boa, atm) and heating rate (SWHR) due to shortwave radiation. The right panel explains the same variable in long wave spectrums of radiation. The simulated shortwave top of the atmosphere forcing (SWRFtoa) shows an increasing trend over the NW box and North-central India. A different response is observed for longwave radiative forcing at the top of the atmosphere. It is well-known that dust aerosols show both scattering and absorbing nature at the top of the atmosphere for short wave radiation; however, the net effect is negative (cooling). Hence, a reduction in dust aerosols enhances warming (shortwave trap) at the top of the atmosphere.

Similarly, in the longwave spectrum, dust is absorbing in nature. Therefore, the declining trends in long wave top of the atmosphere radiative forcing (LWRFtoa) agree with the observed trends in dust burden and/or AOD. It is interesting to note that, the longwave cooling trend exceeds the shortwave warming trends both in values and spatial extensions, leading to a net cooling effect at the top of the atmosphere. The nature of the radiative forcing at the surface for the short wave (SWRF boa) and longwave (LWRFboa) shows distinct characteristics. The overall trend is positive for shortwave and low negative for longwave. This might be due to the more (than the average) incoming solar radiation to the surface and more emission of longwave from a surface. For both cases, the decline in the dust 
220 is a favorable condition. It is interesting to note that the spatial extent of dust-related changes in the

221 surface and top of the atmosphere radiative forcing have shown a spread beyond the source region.

222 In addition, a decline in the trend net (shortwave and longwave combined) atmospheric radiative

223 forcing (top minus bottom) is observed.

224 It may further be noted that the spatial trends of short wave forcing are dominant mostly over the

225 NWbox and part of northwestern India. On the other hand, spatial trends of longwave forcing are 226 prevailing over the Eastern regions. The atmospheric radiative forcing explains the amount of 227 radiative flux absorbed or lost by the atmosphere due to the presence of an aerosol species. This is 228 further explained using a matrix called the atmospheric heating rate (SWHR and LWHR in Fig 4) as 229 given in equation 2. The atmospheric heating rate is considered to be a sign of climate implication of 230 aerosols and as calculated from $\mathrm{RF}_{\mathrm{atm}}$ (Singh et al., 2016; Tiwari et al., 2019; Tripathi et al., 2007)

$$
\frac{\delta \mathrm{T}}{\delta \mathrm{t}}=\frac{\mathrm{g}}{\mathrm{C}_{\mathrm{p}}} \frac{\Delta \mathrm{RF}_{\mathrm{atm}}}{\Delta \mathrm{P}}
$$

232 Where, $\mathrm{g}$ is the acceleration due to gravity, $\mathrm{C}_{\mathrm{p}}$ the specific heat of air at constant pressure, and $\mathrm{P}$ is

233 the atmospheric pressure. $\Delta \mathrm{P}$ is the atmospheric pressure difference between the top and bottom 234 boundary of each layer, respectively. As most of the aerosol load (here dust) thereby heating is 235 confined to the lower atmosphere, a constant value of $300 \mathrm{hPa}$ is used for $\Delta \mathrm{P}$ in equation 2 (Singh et 236 al., 2016; Tiwari et al., 2019).

237 From Fig 4, it is clear that the simulated heating rate (both for short wave and long wave) shows a 238 declining trend with an agreement with the aerosol burden and /or atmospheric radiative forcing. It 239 has a more extensive spatio-temporal spread beyond the source region. The negative trend of 240 shortwave exceeds long wave in magnitude. This is attributable to reducing dust, hence the change in 241 atmospheric absorption in both the short and longwave radiation spectrum. The next section 242 quantifies the net changes in dust and associated parameters over the selected region (i.e., NW box).

\subsection{Trends in AOD and precipitation over northwest}

245 Fig.5 depicts the inter-annual variation of the simulated rainfall and AOD, averaged over the NW. 
248 during the summer (month of May) exhibit opposite trends.
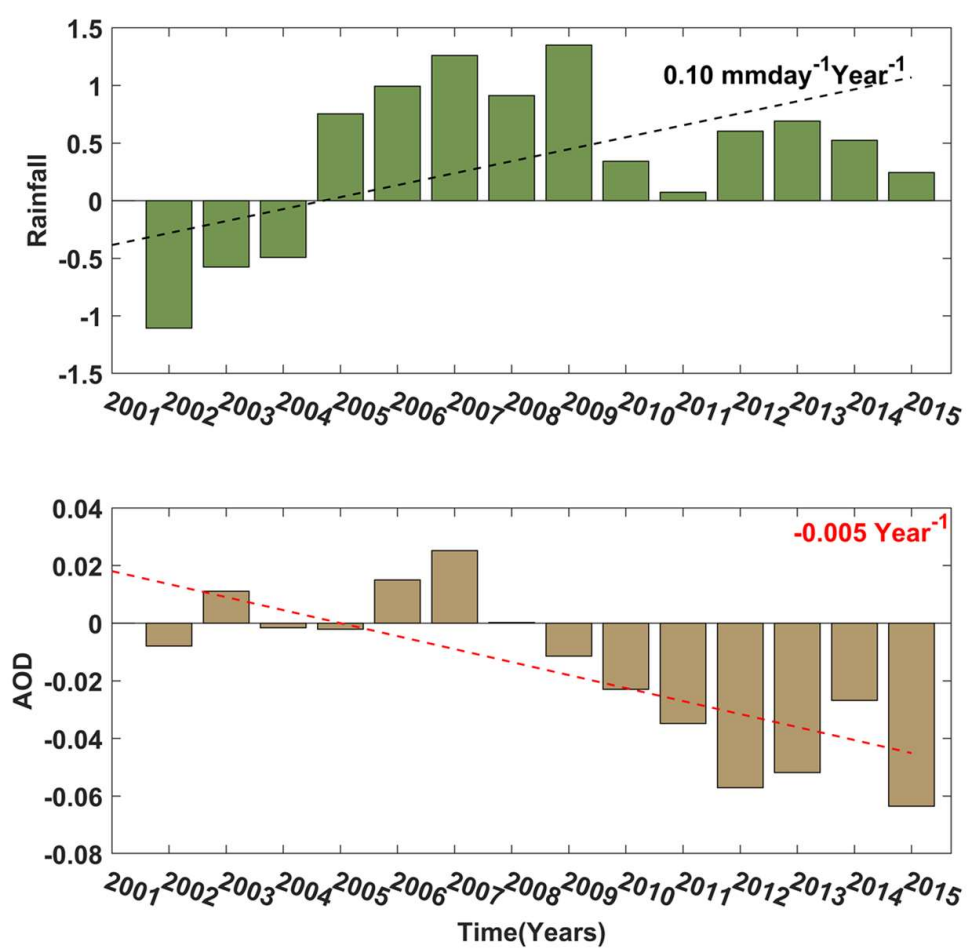

250 Fig.5.Trends (Year ${ }^{-1}$ ) within NW box with respect to the base year (2001) in simulated dust AOD and 251 Precipitation for the period of study over the region of interest (NW part of India and adjacent regions). Trends are significant at the $95 \%$ confidence level determined using the Mann-Kendall trend

The rainfall (top panel of Fig.5) shows a significant positive trend $\left(0.1 \mathrm{~mm} \mathrm{day}^{-1} \mathrm{year}^{-1}, \mathrm{p}<0.05\right)$ with respect to the base year of simulation. On the other hand, AOD in the bottom panel shows a declining trend over the years $\left(0.005\right.$ Year $\left.^{-1}, \mathrm{p}<0.05\right)$. These results show evidence that the atmosphere over the dust source region is getting cleaner over the recent decade as a response to changes in rainfall. Therefore, further changes in rainfall over this region are of importance to regional aerosol loading. The current study thus supports the findings by Pandey et al., 2017 in addition to showing the changes 261 to aerosol radiative effects. This also points to the possibility of using such aerosol-chemistry models 262 for studies related to regional hydrology. Again, the increasing rainfall over the arid /semi-arid region 263 is indicating a change in the regional climate as dust simulated by the model simply responds to the 264 large scale meteorological fields. 
265

266

267

268

269

270

271

272

273

274

275

276

277

\subsection{Trends in dust and the associated changes in radiative forcing}

We estimate the trends and net changes in the dust, rain, and radiative forcing due to shortwave and longwave spectrum (see Table 2) over NW. The inter-annual variation for each parameter is shown in

Fig S2. It may be noted that the anomalies were calculated using a similar approach, as discussed in section 3.4.

Table 2 Area averaged trends of various variables w.r.to year 2001

\begin{tabular}{llccc}
\hline \multicolumn{1}{c}{ Variables } & Units & Trend year $^{-1}$ & Duration & Total change (\%) \\
\hline AOD & unit less & $\mathbf{- 0 . 0 0 5}$ & $2001-2015$ & $-17.5 \%$ \\
Precipitation & $\mathrm{mm} \mathrm{day}^{-1}$ & $\mathbf{0 . 1 0}$ & $2001-2015$ & $54.14 \%$ \\
Burden & $\mathrm{mg} \mathrm{m}^{-2}$ & $\mathbf{- 5 . 4 7}$ & $2001-2015$ & $-19.3 \%$ \\
Surface Emission & $\mathrm{mg} \mathrm{m}^{-2} \mathrm{day}^{-1}$ & -8.38 & $2001-2015$ & $-3.6 \%$ \\
Dry Deposition & $\mathrm{mg} \mathrm{m}^{-2} \mathrm{day}^{-1}$ & $\mathbf{0 . 2 8}$ & $2001-2015$ & $48.6 \%$ \\
Wet deposition & $\mathrm{mg} \mathrm{m}^{-2} \mathrm{day}^{-1}$ & $\mathbf{1 . 6 9}$ & $2001-2015$ & $79.6 \%$ \\
SWRF( toa) & $\mathrm{Wm}^{-2}$ & $\mathbf{0 . 0 4}$ & $2001-2015$ & $7 \%$ \\
SWRF (atm) & $\mathrm{Wm}^{-2}$ & $\mathbf{- 0 . 1 9}$ & $2001-2015$ & $-16.6 \%$ \\
SWRF (boa) & $\mathrm{Wm}^{-2}$ & $\mathbf{0 . 2 4}$ & $2001-2015$ & $11.6 \%$ \\
SWHR (atm) & $\mathrm{Kday}^{-1}$ & $\mathbf{- 0 . 0 0 6}$ & $2001-2015$ & $-16.1 \%$ \\
LWRF (toa) & $\mathrm{Wm}^{-2}$ & $\mathbf{- 0 . 1 4}$ & $2001-2015$ & $-88.6 \%$ \\
LWRF (atm) & $\mathrm{Wm}^{-2}$ & -0.08 & $2001-2015$ & $-32.8 \%$ \\
LWRF (boa) & $\mathrm{Wm}^{-2}$ & $\mathbf{- 0 . 0 9}$ & $2001-2015$ & $-20.8 \%$ \\
LWHR (atm) & $\mathrm{Kday}^{-1}$ & -0.002 & $2001-2015$ & $-22.5 \%$ \\
\hline
\end{tabular}

Bold numbers indicate statistically significant trends $(\mathrm{p}<0.05)$.

Similar to the spatial trends, dust tracer burden and surface emission both exhibit negative trends during the summer season (Month of May). It may be due to the observed increase in rainfall, which makes the atmosphere relatively cleaner, and at the same time, the land surface becomes wetter. A wetter land inhibits soil erosion and dust emission. Further, the increase in wet depositions supports the precipitation link to dust reduction. On the other hand, an increase in dry deposition may be 
278 attributed to the dust particle growth in the presence of additional moisture. Hence, the combined

279 effects of dry and wet deposition and the rainfall might be responsible for the trends of simulated dust

280 aerosol optical depth. The area-averaged temporal trends of shortwave and longwave radiative

281 elements agree with the change in dust load/AOD. It is essential to note that these radiative elements

282 are linked to the state of the climate of a region. Long term changes in any of these variables indicate

283 a change in the regional climate. There are notable alterations observed in the radiative elements

284 during the study period. Though years to year seasonal variations are observed, we have discussed

285 only the mean changes of these elements during summer (May) for the study period. It may be

286 mentioned that regional climate models are meant to simulate the mean and variability, rather than

287 exact quantification of a climate state variable. Area averaged temporal trends in short wave radiative

288 forcing show robust and significant trends $(\mathrm{p}<0.05)$ over its longwave counterparts. The trends in

289 both TOA and BOA radiative forcing components are as expected. Dust aerosols are known to warm

290 the atmosphere by absorbing the incident solar radiation, and this can be quantitatively determined

291 by the atmospheric heating rate. The decrease in aerosol-induced atmospheric heating over south Asia

292 has also been reported in a recent study (Ramachandran et al., 2020, Mukherjee et al., 2021).

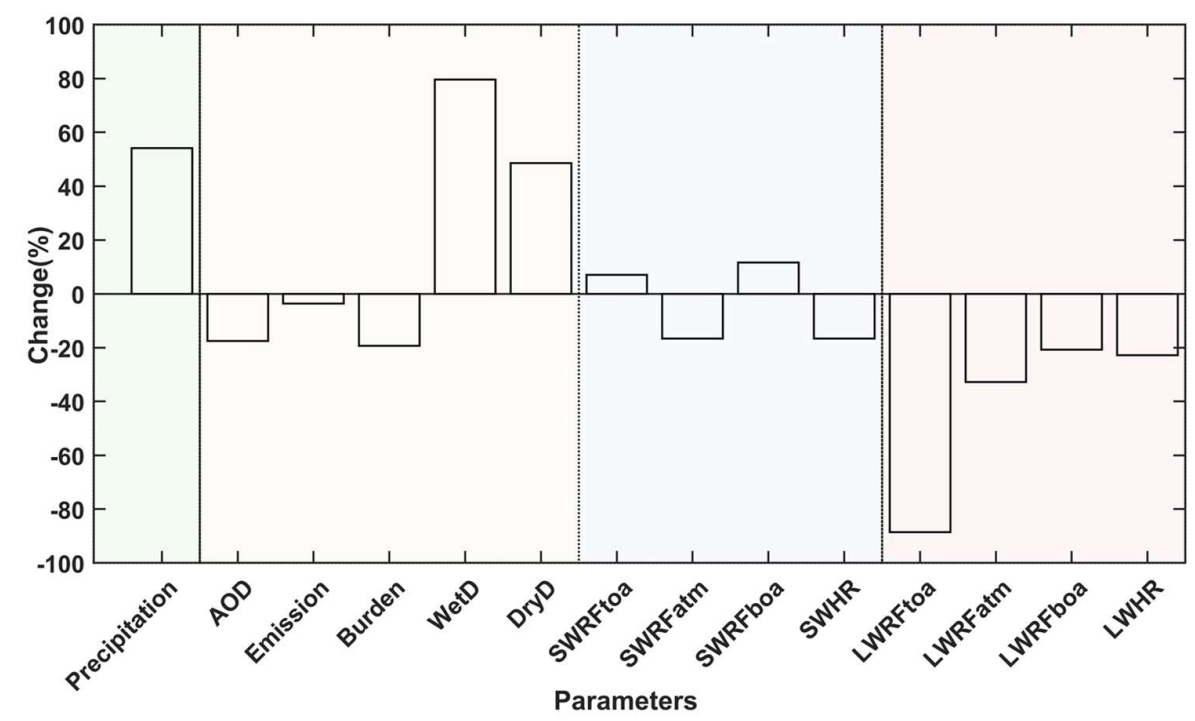

Fig.6. Overall changes (Percentage) in various parameters within the NW box with respect to the base year (2001)). SW, LW, and HR are acronyms for Shortwave, Longwave and Heating rate, respectively. 
298 The overall changes in the above-discussed parameters over the NW box and expressed in percentage

299 (Fig.6). A total change in the AOD with respect to the base year is estimated to be $-17 \%$ and results 300 in a $\sim-19 \%$ decrease in dust burden. The direction and magnitude of the change in burden and AOD 301 are comparable with the earlier studies (Pandey et al.,2017, Pandey et al., 2016) . The precipitation 302 has increased more than $50 \%$ over the semi-arid/desert regions. In addition to that, wet deposition 303 percentage change $(\sim 80 \%)$ exceeds almost twice that of dry depositions change $(\sim 48 \%)$.

304

305

306

307

308

309

There are net increases in the top and bottom of the atmosphere short wave radiative forcing $(7 \%$ and $11.6 \%$, respectively). However, there is an overall decline in the atmospheric heating and atmospheric radiative forcing $(\sim-16 \%)$ in the short wave domain. Though the shortwave radiative forcing and heating rate trends are much higher than those of its longwave counterparts, the change in longwave forcing is more significant in magnitude and mostly negative, as shown in Fig. 6. Further, maximum change is observed in top of the atmosphere LWRF and is approximately $-88 \%$ from that of the base year. It is interesting to note that the LWRFatm responds nearly twice over SWRFatm to a unit change in dust AOD/burden. These results are essential to discern the response of shortwave and longwave forcing to the same factor (here the change in dust)

\subsection{Summary and conclusions}

Regionally, dust aerosols partly offset greenhouse Gas (GHGs) warming due to inhibiting the shortwave radiations from reaching the ground. Further, by warming the atmospheric column, it is linked to various boundary layer processes. Dust aerosols, in both short and long time scales impact the monsoon rainfall over India, as suggested by previous studies (Lau et al., 2008; Lau and Kim, 2015, 2006; Sanap and Pandithurai, 2015; Vinoj et al., 2014). Hence, any change in dust magnitude/spread could affect the regional climate through various forcing and feedback mechanisms. Using a coupled chemistry-climate model with an updated land module (RegCM4.5), we simulated the summer changes in dust over the source regions adjacent to Indian landmass for 15 
324 years (2001-2015) period span. The model performance is found to be reasonable when compared to 325 the observations and is in fair agreement with the findings of earlier studies. In summary,

326 1. The simulated AOD is found to exhibit a spatio-temporal declining trend, whereas rainfall 327 shows an increasing trend over the arid/desert and semi-arid regions of NW India.

2. The change in AOD could be to be due to the combined effects of rainfall and tracer processes (emission, transport, and removal/deposition). There is an approximately $18 \%$ decline in AOD and $>50 \%$ rainfall enhancement observed over NW parts of India.

3. The trend of wet removal is more than five folds dominant over the gravity settling/dry deposition. However, the net change in a wet removal is nearly twice that of dry deposition.

4. The direction of the observed trend in radiative forcing in both short wave and longwave radiation regimes agrees with the change in dust load/burden. However, the short wave forcing trends are dominant over its longwave counterparts.

5. The longwave radiative forcing is more sensitive to a unit change in dust burden/AOD compared to shortwave radiative forcing.

6. As a response to dust change, a significant widespread atmospheric cooling trend is observed over parts of North and North-western India. 
Author contributions: AA, VV, and SP designed the study. AA performed the model simulations and wrote the first draft. VV, AA and SP contributed equally in discussions and finalized the paper.

\section{Acknowledgment}

AA is thankful to the Department of Science and Technology Government of India for providing INSPIRE fellowship for doctoral research. We are thankful to International Centre for Theoretical Physics (ICTP) for providing RegCM 4.5 source code. We are also thankful to the developers from Max Planck Institute für Meteorologie and National Center for Atmospheric Research (NCAR) for providing open-source software like CDO and NCL, which are used in this study. VV thanks ISRO for support through its ARFINET program. The authors are thankful to Director NCPOR for constant encouragement and support. IIT Bhubaneswar is acknowledged for providing the necessary infrastructure during this research was carried out.

\section{References}

Abish, B., Arun, K., 2019. Resolving the weakening of orographic rainfall over India using a regional climate model RegCM 4.5. Atmos. Res. 227, 125-139. https://doi.org/10.1016/j.atmosres.2019.05.003

Ajay, P., Pathak, B., Solmon, F., Bhuyan, P.K., Giorgi, F., 2019. Obtaining best parameterization scheme of RegCM 4.4 for aerosols and chemistry simulations over the CORDEX South Asia. Clim. Dyn. 53, 329-352. https://doi.org/10.1007/s00382-018-4587-3

Alfaro, S.C., Gomes, L., 2001. Modeling mineral aerosol production by wind erosion: Emission intensities and aerosol size distributions in source areas. J. Geophys. Res. Atmos. 106, 1807518084. https://doi.org/10.1029/2000JD900339@10.1002/(ISSN)2169-8996.DUST1

Atwater, M.A., 1970. Planetary albedo changes due to aerosols. Science (80-. ). 170, 64-66. https://doi.org/10.1126/science.170.3953.64

Bollasina, M., Nigam, S., Lau, K.M., 2008. Absorbing aerosols and summer monsoon evolution over South Asia: An observational portrayal. J. Clim. 21, 3221-3239. https://doi.org/10.1175/2007JCLI2094.1

Charlson, R.J., Schwartz, S.E., Hales, J.M., Cess, R.D., Coakley, J.A., Hansen, J.E., Hofmann, D.J., 1992. Climate forcing by anthropogenic aerosols. Science (80-. ). 255, 423-430. https://doi.org/10.1126/science.255.5043.423

Chung, C.E., Ramanathan, V., Kiehl, J.T., Chung, C.E., Ramanathan, V., Kiehl, J.T., 2002. Effects 
of the South Asian Absorbing Haze on the Northeast Monsoon and Surface-Air Heat Exchange. J. Clim. 15, 2462-2476. https://doi.org/10.1175/15200442(2002)015<2462:EOTSAA>2.0.CO;2

Das, S., Dey, S., Dash, S.K., 2015a. Direct radiative effects of anthropogenic aerosols on Indian summer monsoon circulation. Theor. Appl. Climatol. https://doi.org/10.1007/s00704-0151444-8

Das, S., Dey, S., Dash, S.K., 2015b. Impacts of aerosols on dynamics of Indian summer monsoon using a regional climate model. Clim. Dyn. 44, 1685-1697. https://doi.org/10.1007/s00382014-2284-4

Dash, S.K., Mamgain, A., Pattnayak, K.C., Giorgi, F., 2013. Spatial and Temporal Variations in Indian Summer Monsoon Rainfall and Temperature: An Analysis Based on RegCM3 Simulations. Pure Appl. Geophys. 170, 655-674. https://doi.org/10.1007/s00024-012-0567-4

Dash, S.K., Mishra, S.K., Pattnayak, K.C., Mamgain, A., Mariotti, L., Coppola, E., Giorgi, F., Giuliani, G., 2015. Projected seasonal mean summer monsoon over India and adjoining regions for the twenty-first century. Theor. Appl. Climatol. 122, 581-593. https://doi.org/10.1007/s00704-014-1310-0

Davitashvili, T., Kutaladze, N., Kvatadze, R., Mikuchadze, G., 2018. Effect of dust aerosols in forming the regional climate of Georgia. Scalable Comput. 19, 87-96. https://doi.org/10.12694/scpe.v19i2.1398

Dee, D.P., Uppala, S.M., Simmons, A.J., Berrisford, P., Poli, P., Kobayashi, S., Andrae, U., Balmaseda, M.A., Balsamo, G., Bauer, P., Bechtold, P., Beljaars, A.C.M., van de Berg, L., Bidlot, J., Bormann, N., Delsol, C., Dragani, R., Fuentes, M., Geer, A.J., Haimberger, L., Healy, S.B., Hersbach, H., Hólm, E. V., Isaksen, L., Kållberg, P., Köhler, M., Matricardi, M., Mcnally, A.P., Monge-Sanz, B.M., Morcrette, J.J., Park, B.K., Peubey, C., de Rosnay, P., Tavolato, C., Thépaut, J.N., Vitart, F., 2011. The ERA-Interim reanalysis: Configuration and performance of the data assimilation system. Q. J. R. Meteorol. Soc. 137, 553-597. https://doi.org/10.1002/qj.828

Deepshikha, S., Satheesh, S.K., Srinivasan, J., 2006. Dust aerosols over India and adjacent continents retrieved using METEOSAT infrared radiance Part I: Sources and regional distribution. Ann. Geophys. 24, 37-61. https://doi.org/10.5194/angeo-24-37-2006

Dey, S., Tripathi, S.N., Singh, R.P., Holben, B.N., 2004. Influence of dust storms on the aerosol optical properties over the Indo-Gangetic basin. J. Geophys. Res. D Atmos. 109, D20211. https://doi.org/10.1029/2004JD004924

Dickinson, R.E., Errico, R.M., Giorgi, F., Bates, G.T., 1989. A regional climate model for the western United States. Clim. Change 15, 383-422. https://doi.org/10.1007/BF00240465

Dipu, S., Prabha, T. V., Pandithurai, G., Dudhia, J., Pfister, G., Rajesh, K., Goswami, B.N., 2013. Impact of elevated aerosol layer on the cloud macrophysical properties prior to monsoon onset. Atmos. Environ. 70, 454-467. https://doi.org/10.1016/j.atmosenv.2012.12.036

Ensor, D.S., Porch, W.M., Pilat, M.J., Charlson, R.J., 1971. Influence of the Atmospheric Aerosol on Albedo. J. Appl. Meteorol. 10, 1303-1306. https://doi.org/10.1175/15200450(1971)010<1303:iotaao $>2.0 . c 0 ; 2$

Gao, X., Xu, Y., Zhao, Z., Pal, J.S., Giorgi, F., 2006. On the role of resolution and topography in the simulation of East Asia precipitation. Theor. Appl. Climatol. 86, 173-185. https://doi.org/10.1007/s00704-005-0214-4

Georg a, G., Dudhia, J., Stauffer, D.R., 1994. A description of the Fifth-generation Penn 
State/NCAR Mesoscale Model (MM5). NCAR Tech. Note NCAR/TN-398+STR 121. https://doi.org/10.5065/D60Z716B

Giorgi, F., 2019. Thirty Years of Regional Climate Modeling: Where Are We and Where Are We Going next? J. Geophys. Res. Atmos. 124, 5696-5723. https://doi.org/10.1029/2018JD030094

Giorgi, F., Coppola, E., Solmon, F., Mariotti, L., Sylla, M.B., Bi, X., Elguindi, N., Diro, G.T., Nair, V., Giuliani, G., Turuncoglu, U.U., Cozzini, S., Güttler, I., O’Brien, T.A., Tawfik, A.B., Shalaby, A., Zakey, A.S., Steiner, A.L., Stordal, F., Sloan, L.C., Brankovic, C., 2012. RegCM4: Model description and preliminary tests over multiple CORDEX domains. Clim. Res. 52, $7-$ 29. https://doi.org/10.3354/cr01018

Giorgi, F., Marinucci, M.R., 1991. Validation of a regional atmospheric model over Europe:

Sensitivity of wintertime and summertime simulations to selected physics parametrizations and lower boundary conditions. Q. J. R. Meteorol. Soc. 117, 1171-1206. https://doi.org/10.1002/qj.49711750204

Giorgi, F., Solmon, F., Giuliani, G., 2016. Regional Climatic Model RegCM User's Guide Version 4.5 .

Gu, Y., Liou, K.N., Jiang, J.H., Su, H., Liu, X., 2012. Dust aerosol impact on North Africa climate: A GCM investigation of aerosol-cloud-radiation interactions using A-Train satellite data. Atmos. Chem. Phys. 12, 1667-1679. https://doi.org/10.5194/acp-12-1667-2012

Harikishan, G., Padmakumari, B., Maheskumar, R.S., Kulkarni, J.R., 2015. Radiative effect of dust aerosols on cloud microphysics and meso-scale dynamics during monsoon breaks over Arabian sea. Atmos. Environ. 105, 22-31. https://doi.org/10.1016/j.atmosenv.2015.01.037

Hess, M., Koepke, P., Schult, I., 1998. Optical Properties of Aerosols and Clouds: The Software Package OPAC. Bull. Am. Meteorol. Soc. 79, 831-844. https://doi.org/10.1175/15200477(1998)079<0831:OPOAAC $>2.0 . \mathrm{CO} ; 2$

Holtslag, A.A.M., De Bruijn, E.I.F., Pan, H.L., 1990. A high resolution air mass transformation model for short-range weather forecasting. Mon. Weather Rev. 118, 1561-1575. https://doi.org/10.1175/1520-0493(1990)118<1561:AHRAMT>2.0.CO;2

I Tengen, I.F., 1995. Contribution to the atmospheric mineral aerosol load from land surface modification. J. Geophys. Res. 100, 707-18,726.

Jin, Q., Wei, J., Yang, Z.L., Pu, B., Huang, J., 2015. Consistent response of Indian summer monsoon to Middle East dust in observations and simulations. Atmos. Chem. Phys. 15, 9897-9915. https://doi.org/10.5194/acp-15-9897-2015

Kiehl, J.T., Hack, J.J., Bonan, G.B., Boville, B.A., Briegleb, B.P., Williamson, D.L., Rasch, P.J., 1996. Description of the NCAR Community Climate Model (CCM3).

Lau, K.-M., Kim, K.-M., 2015. Impacts of absorbing aerosols on the Asian monsoon: An interim assessment.

Lau, K.-M., Ramanathan, V., Wu, G.-X., Li, Z., Tsay, S.C., Hsu, C., Sikka, R., Holben, B., Lu, D., Tartari, G., Chin, M., Koudelova, P., Chen, H., Ma, Y., Huang, J., Taniguchi, K., Zhang, R., 2008. THE JOINT AEROSOL- MONSOON EXPERIMENT A New Challenge for Monsoon Climate Research Understanding the physical processes responsible for aerosol- monsoon water cycle interactions is fundamental to improving prediction and enhancing vigilance of climatic ha. Am. Meteorol. Soc.

Lau, K.M., Kim, K.-M., Hsu, N.C., Holben, B.N., 2009. Possible influences of air pollution,dustand sandstorms on the Indain monsoon. WMO Bull. 58. 
462

463

464

465

466

467

468

469

470

471

472

473

474

475

476

477

478

479

480

481

482

483

484

485

486

487

488

489

490

491

492

493

494

495

496

497

498

499

500

501

502

503

504

505

Lau, K.M., Kim, K.M., 2011. Comment on “" Elevated heat pump' hypothesis for the aerosol monsoon hydroclimate link : 'Grounded 'in observations ?" by S . Nigam and M . Bollasina 116, 4-7. https://doi.org/10.1029/2010JD014800

Lau, K.M., Kim, K.M., 2006. Observational relationships between aerosol and Asian monsoon rainfall, and circulation. Geophys. Res. Lett. 33, 1-5. https://doi.org/10.1029/2006GL027546

Lau, K.M., Kim, M.K., Kim, K.M., 2006. Asian summer monsoon anomalies induced by aerosol direct forcing: The role of the Tibetan Plateau. Clim. Dyn. 26, 855-864. https://doi.org/10.1007/s00382-006-0114-z

Lau, W., 2014. Atmospheric science: Desert dust and monsoon rain. Nat. Geosci. https://doi.org/10.1038/ngeo2115

Lau, W.K.M., 2016. The aerosol-monsoon climate system of Asia: A new paradigm. J. Meteorol. Res. 30, 1-11. https://doi.org/10.1007/s13351-015-5999-1

Lau, W.K.M., Lau, K.M., Lau, W.K.M., 2016. The aerosol-monsoon climate system of Asia: A new paradigm. J. Meteorol. Res. 30, 1-11. https://doi.org/10.1007/s13351-015-5999-1

Maharana, P., Dimri, A.P., Choudhary, A., 2019. Redistribution of Indian summer monsoon by dust aerosol forcing. Meteorol. Appl. 26, 584-596. https://doi.org/10.1002/met.1786

Maurya, R.K.S., Sinha, P., Mohanty, M.R., Mohanty, U.C., 2017. Coupling of Community Land Model with RegCM4 for Indian Summer Monsoon Simulation. Pure Appl. Geophys. 174, 4251-4270. https://doi.org/10.1007/s00024-017-1641-8

Mohanty, M.R., Sinha, P., Maurya, R.K.S., Mohanty, U.C., 2019. Moisture flux adjustments in RegCM4 for improved simulation of Indian summer monsoon precipitation. Clim. Dyn. 52, 7049-7069. https://doi.org/10.1007/s00382-018-4564-x

Nair, V.S., Solmon, F., Giorgi, F., Mariotti, L., Babu, S.S., Moorthy, K.K., 2012. Simulation of South Asian aerosols for regional climate studies. J. Geophys. Res. Atmos. 117, 1-17. https://doi.org/10.1029/2011JD016711

Nigam, S., Bollasina, M., 2010. "Elevated heat pump" hypothesis for the aerosol-monsoon hydroclimate link: "Grounded" in observations? J. Geophys. Res. Atmos. 115, 4-10. https://doi.org/10.1029/2009JD013800

Oh, S.-G., Park, J.-H., Lee, S.-H., Suh, M.-S., 2014. Assessment of the RegCM4 over East Asia and future precipitation change adapted to the RCP scenarios. J. Geophys. Res. Atmos. 119, 29132927. https://doi.org/10.1002/2013JD020693

Pal, J.S., Small, E.E., Eltahir, E.A.B., 2000. Simulation of regional-scale water and energy budgets: Representation of subgrid cloud and precipitation processes within RegCM. J. Geophys. Res. Atmos. 105, 29579-29594. https://doi.org/10.1029/2000JD900415

Pandey, S.K., Bakshi, H., Vinoj, V., 2016. Recent changes in dust and its impact on aerosol trends over the Indo-Gangetic Plain (IGP), in: Im, E., Kumar, R., Yang, S. (Eds.), Remote Sensing of the Atmosphere, Clouds, and Precipitation VI. SPIE, p. $98761 \mathrm{Z}$. https://doi.org/10.1117/12.2223314

Pandey, S.K., Vinoj, V., Landu, K., Babu, S.S., 2017. Declining pre-monsoon dust loading over South Asia: Signature of a changing regional climate. Sci. Rep. 7, 1-10. https://doi.org/10.1038/s41598-017-16338-w

Pattnayak, K.C., Panda, S.K., Saraswat, V., Dash, S.K., 2019. How good is regional climate model version 4 in simulating the monsoon onset over Kerala? Int. J. Climatol. 39, 2197-2208. https://doi.org/10.1002/joc.5945 
506

507

508

509

510

511

512

513

514

515

516

517

518

519

520

521

522

523

524

525

526

527

528

529

530

531

532

533

534

535

536

537

538

539

540

541

542

543

544

545

546

547

548

549
Pattnayak, K.C., Panda, S.K., Saraswat, V., Dash, S.K., 2018. Assessment of two versions of regional climate model in simulating the Indian Summer Monsoon over South Asia CORDEX domain. Clim. Dyn. 50, 3049-3061. https://doi.org/10.1007/s00382-017-3792-9

Ramachandran, S., Rupakheti, M., Lawrence, M.G., 2020. Aerosol - induced atmospheric heating rate decreases over South and East Asia as a result of changing content and composition. Sci. Rep. 1-17. https://doi.org/10.1038/s41598-020-76936-z

Sanap, S.D., Pandithurai, G., 2015. The effect of absorbing aerosols on Indian monsoon circulation and rainfall: A review. Atmos. Res. 164-165, 318-327. https://doi.org/10.1016/j.atmosres.2015.06.002

Santese, M., Zakey, A.S., Giorgi, F., Perrone, M.R., 2003. Aerosol modeling for regional climate studies : application to a dust event over a Mediterranean domain 297502.

Satheesh, S.K., Srinivasan, J., 2002. Enhanced aerosol loading over Arabian Sea during the premonsoon season: Natural or anthropogenic? Geophys. Res. Lett. 29, 21-1-21-4. https://doi.org/10.1029/2002GL015687

Singh, A., Tiwari, Shani, Sharma, D., Singh, D., Tiwari, Suresh, Srivastava, A.K., Rastogi, N., Singh, A.K., 2016. Characterization and radiative impact of dust aerosols over northwestern part of India: a case study during a severe dust storm. Meteorol. Atmos. Phys. 128, 779-792. https://doi.org/10.1007/s00703-016-0445-1

Solmon, F., Giorgi, F., Liousse, C., 2006. Aerosol modelling for regional climate studies: Application to anthropogenic particles and evaluation over a European/African domain. Tellus, Ser. B Chem. Phys. Meteorol. 58, 51-72. https://doi.org/10.1111/j.1600-0889.2005.00155.x

Steiner, A.L., Pal, J.S., Rauscher, S.A., Bell, J.L., Diffenbaugh, N.S., Boone, A., Sloan, L.C., Giorgi, F., 2009. Land surface coupling in regional climate simulations of the West African monsoon. Clim. Dyn. 33, 869-892. https://doi.org/10.1007/s00382-009-0543-6

Tiwari, P.R., Chandra Kar, S., Mohanty, U.C., Dey, S., Sinha, P., Raju, P.V.S., Shekhar, M.S., 2015. The role of land surface schemes in the regional climate model (RegCM) for seasonal scale simulations over Western Himalaya. Atmosfera 28, 129-142. https://doi.org/10.20937/ATM.2015.28.02.05

Tiwari, S., Kumar, A., Pratap, V., Singh, A.K., 2019. Assessment of two intense dust storm characteristics over Indo - Gangetic basin and their radiative impacts: A case study. Atmos. Res. 228, 23-40. https://doi.org/10.1016/j.atmosres.2019.05.011

Tripathi, S.N., Srivastava, A.K., Dey, S., Satheesh, S.K., Krishnamoorthy, K., 2007. The vertical profile of atmospheric heating rate of black carbon aerosols at Kanpur in northern India. Atmos. Environ. 41, 6909-6915. https://doi.org/10.1016/j.atmosenv.2007.06.032

Twomey, S., 1977. The Influence of Pollution on the Shortwave Albedo of Clouds. J. Atmos. Sci. 34, 1149-1152. https://doi.org/10.1175/1520-0469(1977)034<1149:tiopot>2.0.co;2

Vinoj, V., Rasch, P.J., Wang, H., Yoon, J.H., Ma, P.L., Landu, K., Singh, B., 2014. Short-term modulation of Indian summer monsoon rainfall by West Asian dust. Nat. Geosci. 7, 308-313. https://doi.org/10.1038/ngeo2107

Vinoj, V., Satheesh, S.K., 2003. Measurements of aerosol optical depth over Arabian Sea during summer monsoon season. Geophys. Res. Lett. 30. https://doi.org/10.1029/2002g1016664

Zakey, A.S., Solmon, F., Giorgi, F., 2006. Implementation and testing of a desert dust module in a regional climate model. Atmos. Chem. Phys. 6, 4687-4704. https://doi.org/10.5194/acp-64687-2006 
550

551

552

553

554

555 

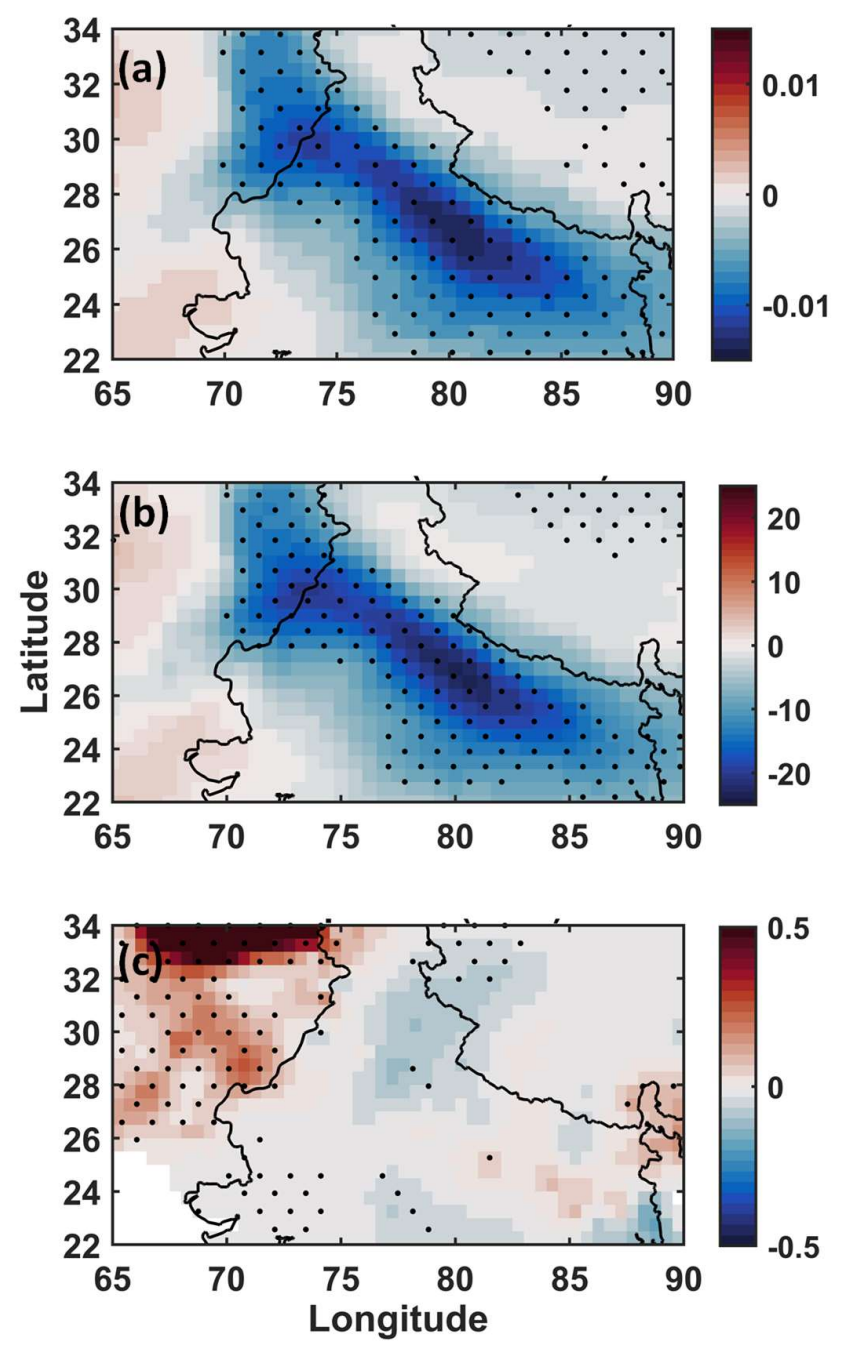

558 Fig.S1. Trends (Year-1) for pre-monsoon simulated (a) dust AOD, (b) Dust burden (mg m ${ }^{-2}$ day $^{-1}$ ), and 559 (c) precipitation $\left(\mathrm{mm} \mathrm{day}^{-1}\right)$ from MERRA-2 and Udel, respectively with respect to the base year 560 (2001). Stipple shows the area where trends are significant at the $95 \%$ confidence level, determined 561 using Mann-Kendall Trend Tests. 

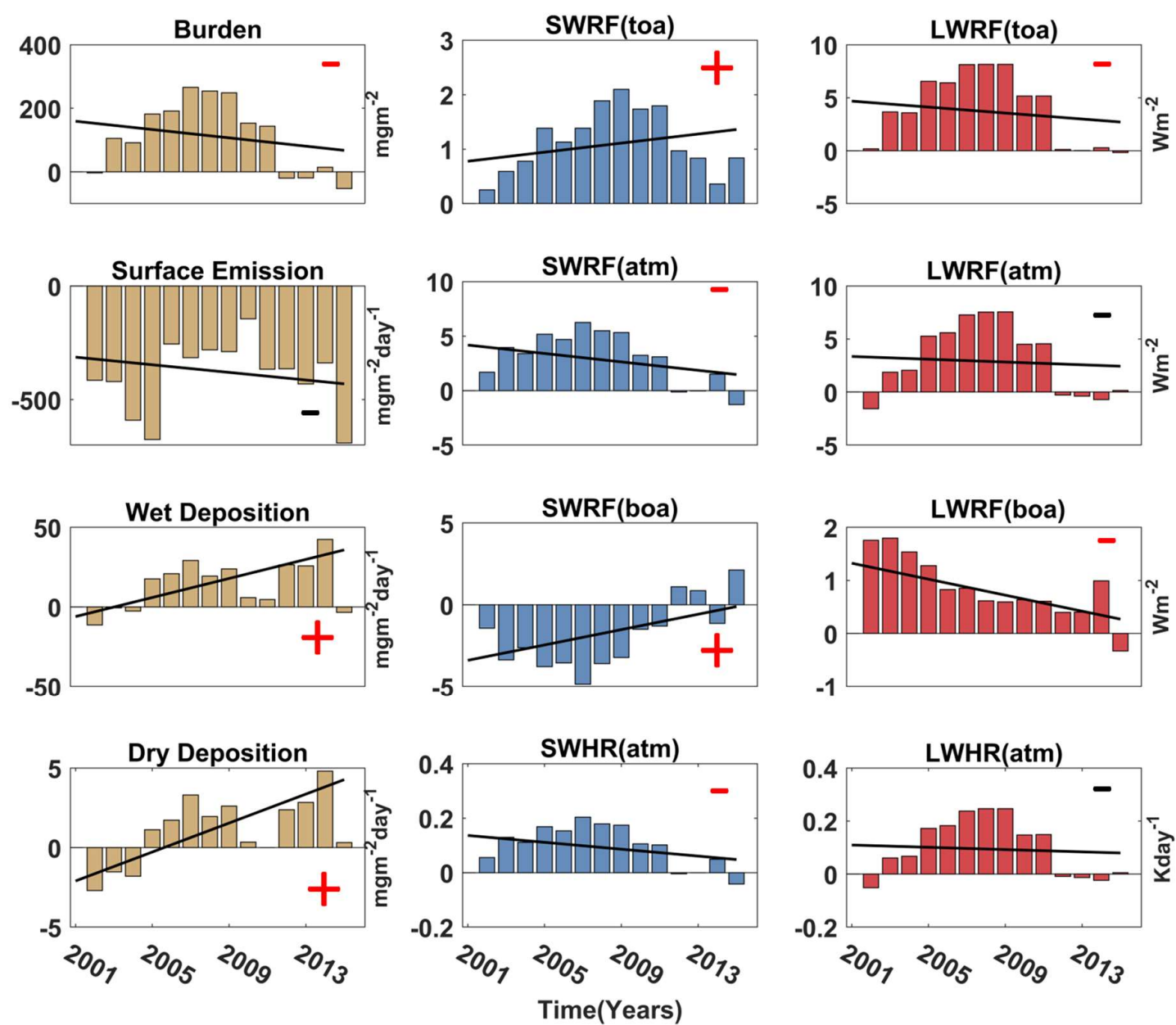

Fig.S2. Trends within the NW box with respect to the base year (2001) in various parameters with the corresponding sign (positive/negative). SW, LW, and HR are acronyms for Shortwave, Longwave and Heating rate, respectively. The plus and minus signs show the nature of trend (with red colour for significant and black for insignificant trend) determined using Mann-Kendall trend test. The actual units of each variable are provided with each plot. 